\title{
The Morphogenesis of the Zebrafish Eye, Including a Fate Map of the Optic Vesicle
}

\author{
ZHENG LI, NANCY M. JOSEPH, AND STEPHEN S. EASTER, JR.* \\ Biology Department, University of Michigan, Ann Arbor, Michigan
}

\begin{abstract}
We have examined the morphogenesis of the zebrafish eye, from the flat optic vesicle at 16 hours post fertilization (hpf) to the functional hemispheric eye at $72 \mathrm{hpf}$. We have produced three-dimensional reconstructions from semithin sections, measured volumes and areas, and produced a fate map by labeling clusters of cells at 14-15 hpf and finding them in the $24 \mathrm{hpf}$ eye cup. Both volume and area increased sevenfold, with different schedules. Initially (16-33 hpf), area increased but volume remained constant; later (33-72 hpf) both increased. When the volume remained constant, the presumptive pigmented epithelium (PE) shrank and the presumptive neural retina (NR) enlarged. The fate map revealed that during 14-24 hpf cells changed layers, moving from the PE into the NR, probably through involution around the margin of the eye. The transformation of the flat epithelial layers of the vesicle into their cup-shaped counterparts in the eye was also accompanied by cellular rearrangements; most cells in a cluster labeled in the vesicle remained neighbors in the eye cup, but occasionally they were separated widely. This description of normal zebrafish eye development provides explanations for some mutant phenotypes and for the effects of altered retinoic acid. Dev Dyn 2000;218:175-188. ๑ 2000 Wiley-Liss, Inc.
\end{abstract}

Key words: zebrafish; fate map; optic vesicle; retina; morphogenesis; growth

\section{INTRODUCTION}

The vertebrate eye begins as an evagination from the anterior end of the neural tube, forming the optic stalk and vesicle. Subsequently the lateral surface of the vesicle invaginates, bringing the thick lateral epithelial layer (LL) adjacent to the thin medial epithelial layer (ML), obliterating the hollow center of the vesicle. The spherical vesicle thus becomes concave outwards, resembling the bowl of a spoon, with the optic stalk as its handle. The shallow bowl becomes deeper and cupshaped as its anterior and posterior sides reach ventrally and laterally to meet one another across the choroid fissure, and thereby encircle the stalk. In this way the hemispheric eye cup is formed, with the neural retina (NR) on the inside and the pigmented epithelium (PE) outside (Walls, 1963; Silver and Sapiro, 1981; Halfter et al., 1985).
The morphogenesis of the zebrafish eye, described by Schmitt and Dowling (1994), is similar, but different in some respects. Their scanning electron micrographs of skinned embryos provided excellent views of the eye, and revealed that the vesicle bypassed the spherical stage; when discerned at about 14 hours post fertilization (hpf), the vesicle was a flattened wing-like structure. The "wing" was initially attached to the neural tube over most of its length, but by $16 \mathrm{hpf}$ had detached from most of the neural tube, the only remaining point of attachment through the optic stalk. The vesicle sagged, so that its erstwhile dorsal and ventral surfaces faced laterally and medially, respectively, and the choroid fissure formed, but caudal to the optic stalk, rather than lateral to it as described above. At $24 \mathrm{hpf}$ the eye cup was essentially spherical, with openings at the pupil and the choroid fissure. The ML was attenuated and pigmented at this stage, and therefore recognizable as the PE, and the LL was a thick pseudostratified columnar epithelium recognizable as the presumptive NR. The first neurons were born 4-5 hours later (Nawrocki, 1985; Hu and Easter, 1999), and continually thereafter (Marcus et al, 1999). By 72 hpf, when the fish could first see (Easter and Nicola, 1996), the eye had enlarged considerably and the optic nerve head was more centrally located than at $24 \mathrm{hpf}$, when its predecessor the optic stalk was attached to the edge of the eye cup (Schmitt and Dowling, 1994; 1996).

Several factors point to the need for a more detailed description of normal eye morphogenesis. The geometric relations of the optic stalk and the eye cup, and of the optic stalk and the choroid fissure, are unexpected, and their transitions to the adult forms are far from obvious. The relative volumes of the two tissues within the eye (PE and NR) change radically, which raises the question of how this is accomplished, e.g., by differential rates of growth of both, or by a shift of cells from the one to the other. Genetically mutant eyes have been described (Furutani-Seiki et al., 1996), including some that show retarded growth, and experimentally

Grant sponsor: National Eye Institute; Grant number: R01EY00168; Grant sponsor: National Science Foundation; Grant number: DIR 9014275.

Z. Li's present address is Parke Davis Pharmaceutical Research, 2800 Plymouth Road, Ann Arbor, MI 48105.

*Correspondence to: Prof. Stephen S. Easter, Jr., Department of Biology, University of Michigan, 830 N. University Avenue, Ann Arbor, MI 48109-1048. E-mail: sseaster@umich.edu

Received 1 December 1999; Accepted 14 February 2000 
altered retinoic acid levels produce abnormal eyes in wild type zebrafish (Hyatt et al., 1992; 1996; MarshArmstrong et al., 1994), but the alterations in the developmental program that lead to these abnormalities can not be known without a better understanding of the normal program. Accordingly, we have investigated the morphogenesis of the zebrafish eye by reconstructing it in three dimensions, to reveal more fully its shape and size; by measuring eye volume and retinal area, to provide a quantitative description of the transformation; and by constructing a fate map of the vesicle, to reveal cellular rearrangements.

Some of these results have been presented previously in abstract form ( $\mathrm{Li}$ and Easter, 1997).

\section{RESULTS \\ Growth and Morphogenesis}

Representative sections (Fig. 1) illustrate the morphological development of the eye. At $16 \mathrm{hpf}$ (Fig. 1A) the flattened optic vesicle comprised two epithelial layers separated by the optic lumen. The lateral layer (LL) was columnar and uniformly thick. The medial layer (ML) was slightly thinner, and cell shape varied gradually from cuboidal at the dorsal rim to columnar more ventrally. Over the next few hours the flat vesicle became cup-shaped and its two layers acquired different characteristics. In the ML, the cuboidal cells flattened into a squamous epithelium (Fig. 1B) which gradually spread ventrally and laterally (Fig. 1C) until it occupied the entire ML and became pigmented, recognizable as the pigmented epithelium (PE), by $24 \mathrm{hpf}$ (Fig. 1D). The LL remained columnar and thickened considerably to become the neural retina (NR). At $36 \mathrm{hpf}$ (Fig. $1 \mathrm{E})$, the qualitative appearance was essentially the same as at $24 \mathrm{hpf}$, but the eye was larger and the cell density was higher. The ganglion cell layer, the first sign of stratification of the pseudostratified columnar epithelium, was evident a few hours later $(\mathrm{Hu}$ and Easter, 1999).

Figures 2 and $3 \mathrm{~A}$ illustrate in three dimensions the morphogenesis of the eye cup from the optic vesicle. At $16 \mathrm{hpf}$ (Fig. 2A) the optic vesicle was flattened and faced dorsally and laterally. The optic stalk was short and nearly as thick as the vesicle, so the boundaries between neural tube, optic stalk, and optic vesicle were indistinct. By $20 \mathrm{hpf}$ (Fig. 2B), the optic stalk had become thinner and had elongated mediolaterally, so the neural tube was clearly separated from the vesicle, which had elongated rostrocaudally and acquired a slightly concave lateral surface. Its attachment to the stalk produced a spoon-like structure, with the handle (the optic stalk) merging smoothly into the bowl of the spoon (the presumptive eye cup). The long axes of both the stalk and the cup were colinear and roughly parallel to the long axis of the neural tube. By $24 \mathrm{hpf}$ (Fig. $2 \mathrm{C}$ ), the eye was much closer to the neural tube, a result of the medial evagination of the vesicle. Because of the flexure of the neural tube and the attendant change in the embryonic coordinate system (Ross et al.,
1992; Schmitt and Dowling, 1994), the stalk was now attached to the ventral side of the eye. Fig. 3A shows that the stalk emerged from the nasal side of the choroid fissure, in the ventronasal quadrant of the eye. This differs from the ventral/central location of the optic stalk that has been described in amniotes (Silver and Sapiro, 1981; Halfter et al., 1985). The eye was a distorted sphere; the posterior (temporal) side bulged further laterally than the anterior (nasal) side, and the dorsoventral diameter (parallel to the choroid fissure) was a bit longer than the nasotemporal diameter.

During 24-72 hpf the optic nerve attenuated and the eye changed shape (Fig. 3). At $24 \mathrm{hpf}$, there was no optic nerve, as there were no optic nerve fibers, but the presumptive optic nerve, the stalk, joined the ventronasal NR. By 48 and $72 \mathrm{hpf}$, this exit point, the optic nerve head, occupied a more central position in the NR as new retina had been added all around the margin in an annulus (Marcus et al., 1999). As the NR thickened, the transretinal segment of the nerve was roughly as long as the segment from the eye to the brain. The nerve was directed medially and rostrally toward the chiasm at $48 \mathrm{hpf}$, but the rostral component was lost by $72 \mathrm{hpf}$, indicative of a shift in the relative positions of the eye and the chiasm. The lens became more exposed; the 24 hpf eye wrapped around $290^{\circ}$ of its circumference but $72 \mathrm{hpf}$ NR covered only $218^{\circ}$ (Easter and Nicola, 1996). The choroid fissure fused over most of its length and at $72 \mathrm{hpf}$ it remained open only at the pupil.

The eye grew during 16-72 hpf, but at different rates. Early (16-33 hpf), the volume of the eye was essentially constant (Fig. 4A). The least-squares linear regression computed over that period:

$$
\text { Volume }=542,000+0.11 \mathrm{t} \mu \mathrm{m}^{3}
$$

in which t indicates age in hpf, had an $\mathrm{R}^{2}$ value of only 0.14 , so the null hypothesis (constant volume) was not disproved, but if one accepts the values of the computed slope, then the volume changed only $17 \%$ over that period (from 720,000 to $840,000 \mu^{3}$ ). In contrast, the area of apposition between the two layers increased steadily, roughly tripling during this period (Fig. 4B), reflecting the change in shape from flat vesicle to curved eye cup. During the later period (33-72 hpf), the volume increased about fourfold and the area roughly doubled. The most surprising result was the constancy of the volume during 16-33 hpf, when the LL/NR enlarged and the ML/PE shrank (Fig. 1). This suggests that cells moved from the ML/PE to the LL/NR, and raises the more general question of what kind of cell movements occurred within the layers. The next section addresses these questions.

\section{Fate Maps}

Single injections. Clusters of cells in the optic vesicle were labeled by iontophoretic injection of diI $\left(1,1^{\prime}\right.$ dioctadecyl-3,3,3'3'-tetramethylindocarbocyanine per- 

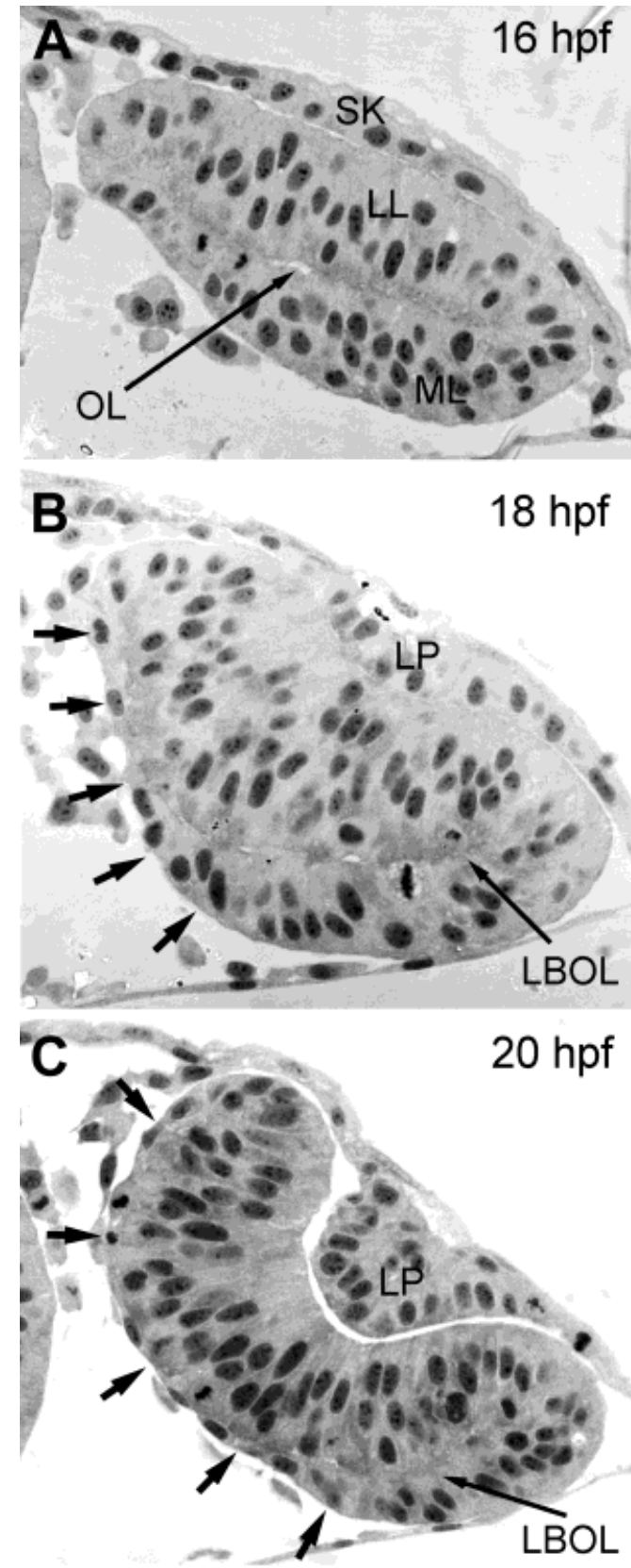

Fig. 1. The transformation of the flattened optic vesicle into the eye cup. Photomicrographs of transverse sections stained with toluidine blue, dorsal up, medial left. Scale bar in E applies to all panels. A: $16 \mathrm{hpf}$. The lateral layer (LL) and the medial layer (ML) were both flat columnar epithelia of nearly equal thickness, separated across the optic lumen (OL) from one another, just deep to the skin (SK). B: $18 \mathrm{hpf}$. The dorsal region of the $\mathrm{ML}$ has begun to flatten, as cells that were previously columnar have become squamous (short arrows). LBOL: lateral boundary of the optic lumen. LP: lens placode. C: $20 \mathrm{hpf}$. The flattening of the dorsal part

chlorate, D-282, Molecular Probes, Eugene, OR) at 14-15 hpf. Most embryos survived and developed normally to $24 \mathrm{hpf}$, at which time the diI signal was nearly as bright as it had been shortly after injection (Fig. 5). Of those fish that developed normally $(\mathrm{n}=56)$, three

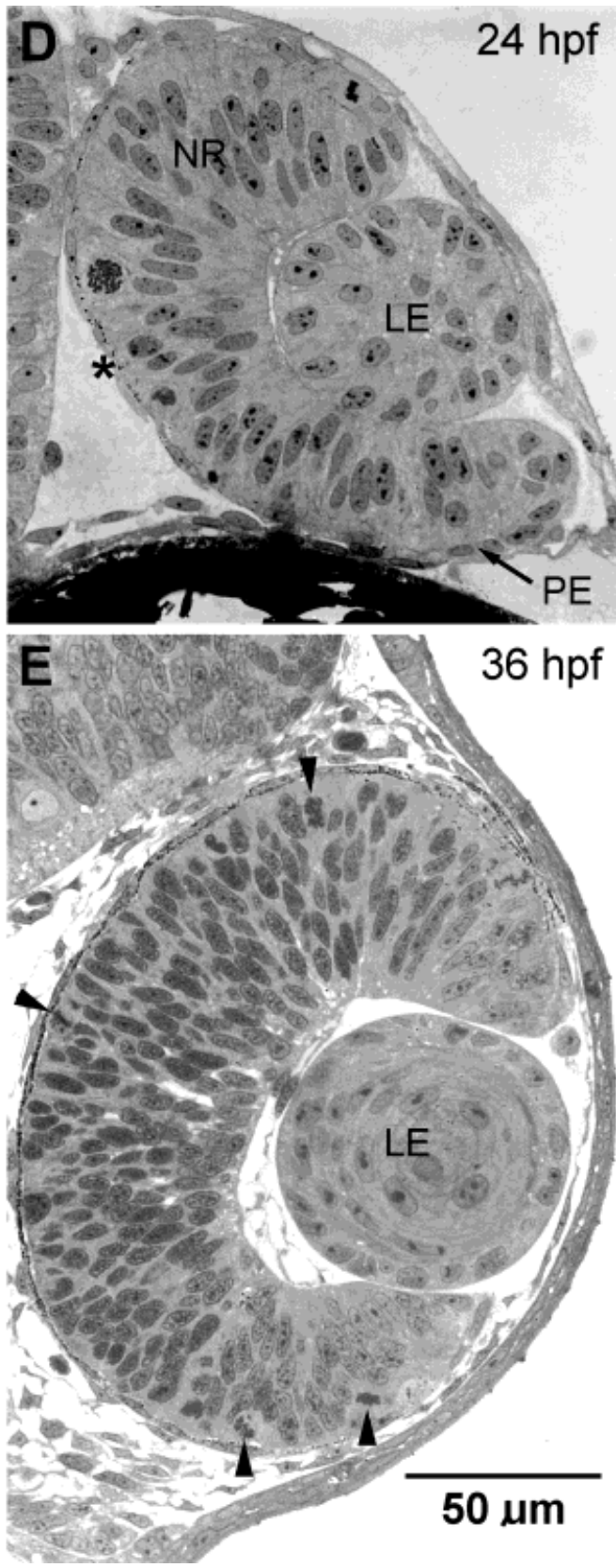

of the ML extended farther ventrally (short arrows) and the remaining columnar epithelium occupied a smaller part of the ML. D: $24 \mathrm{hpf}$. The eye was cup-shaped, as the LL (now the neural retina (NR)) enveloped the LE, and was much thicker than the ML, which was entirely squamous, having lost all its columnar cells. Pigment granules (to the right of *) marked it as the pigmented epithelium (PE). E: 36 hpf. The NR, PE, and LE had enlarged, and the NR contained neurons, but mitotic cells (arrowheads) remain.

classes of results were found. 1) No labeled cells in the NR or the neural tube $(n=8)$. Most commonly these fish had labeled cells in either the lens or the skin, suggesting that the injection had not crossed the enveloping layer. 2) A single cluster of labeled neuroepi- 
A1

A2
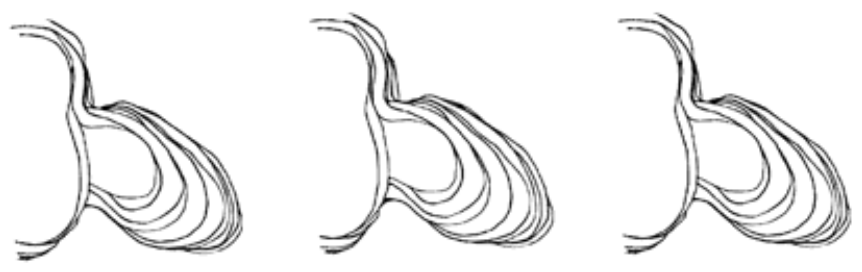

B1
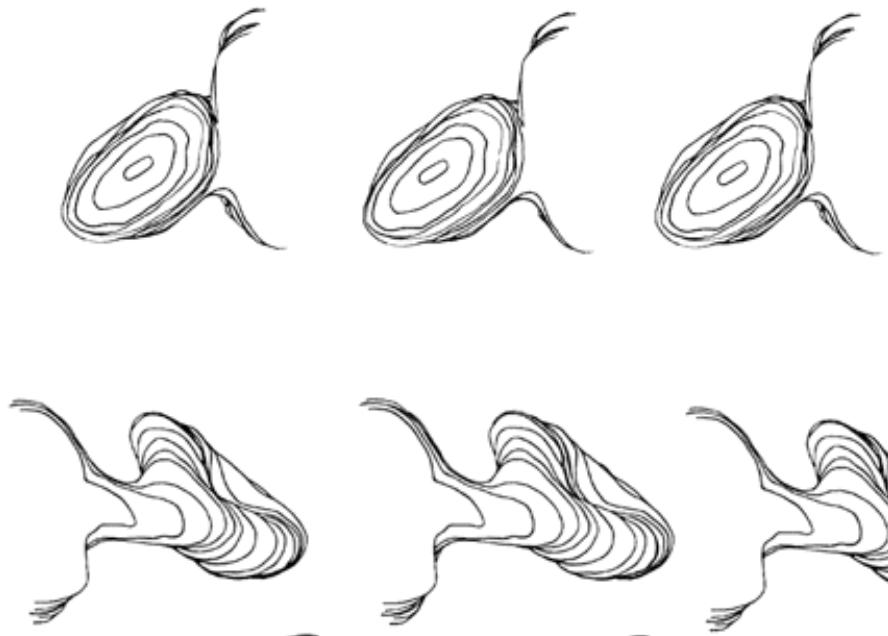

B2
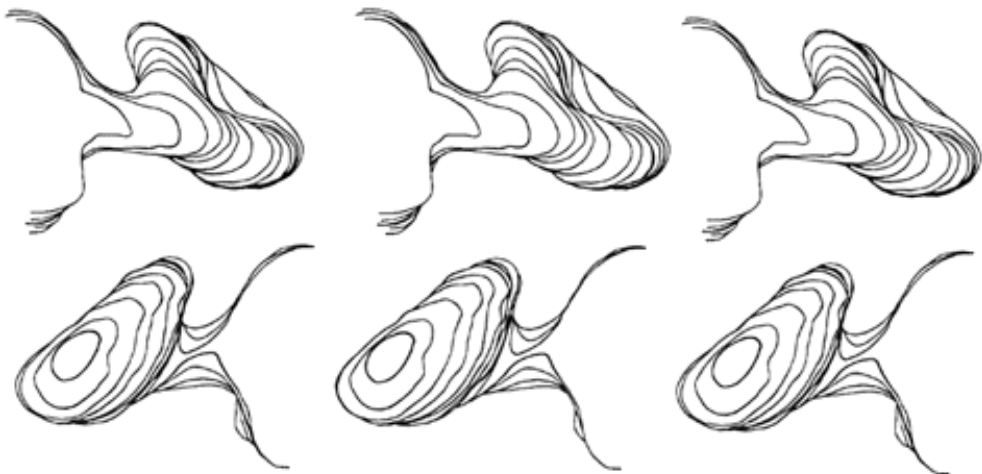

C1
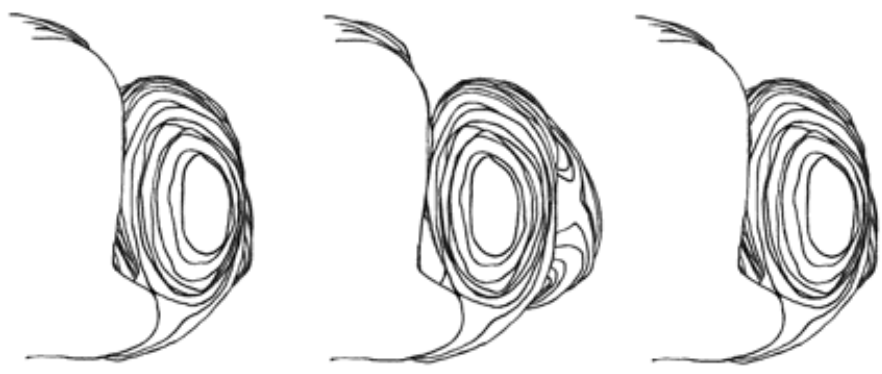

C2
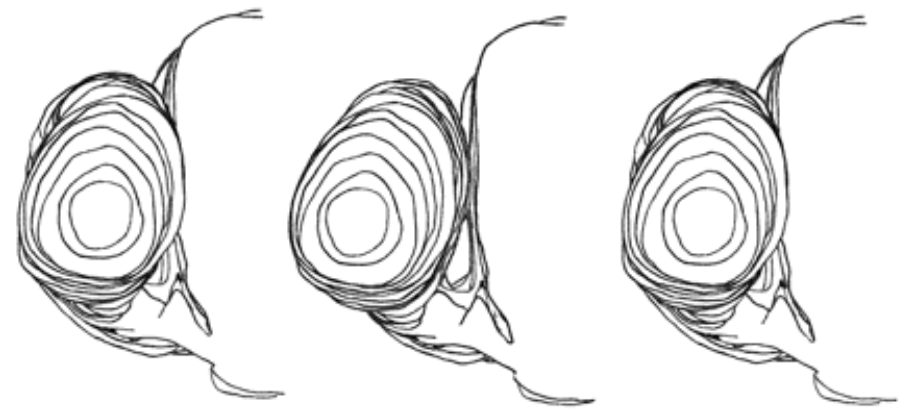

Fig. 2. Stereopairs, with hidden line removal, of three left optic vesicles/eye cups attached to the neural tubes. Row A1 shows an anterior view of the $16 \mathrm{hpf}$ vesicle, and A2 shows the posterior view of this same vesicle. The same convention applies to rows B1 and B2 (20 hpf) and C1

and C2 (24 hpf). Dorsal is up in all. Lateral is to the right in rows 1, and to the left in rows 2 . To obtain 3-dimensions, converge the eyes to fuse the pair on the right or diverge the eyes (or use a prism viewer) to fuse the pair on the left. 


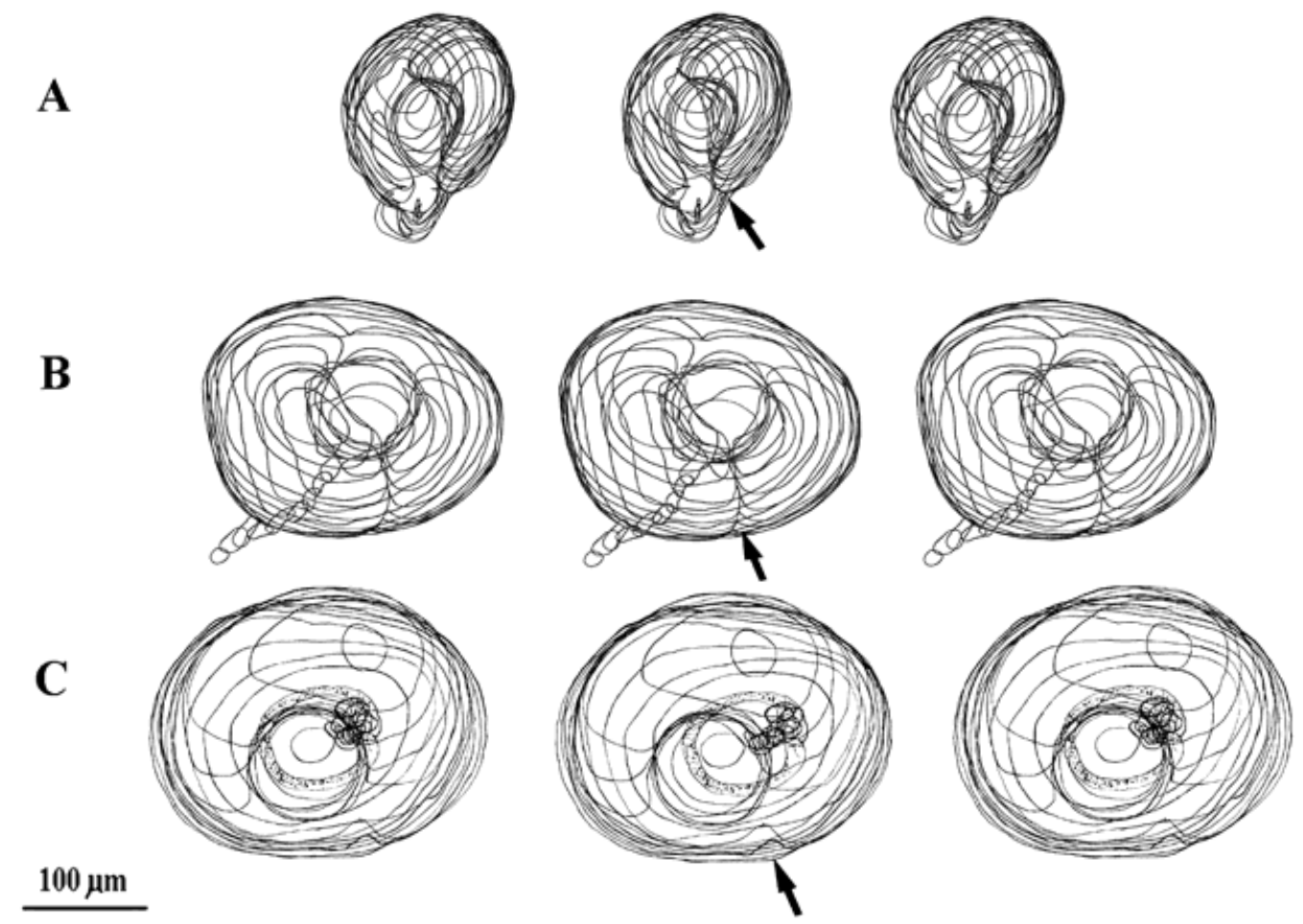

Fig. 3. Stereopairs of three left eyes from embryos of A, 24; B, 48; and C, $72 \mathrm{hpf}$. Lateral views; dorsal is up, anterior (nasal) is to the left. Arrows indicate the choroid fissure. The sections through the optic stalk/nerve include all those up to the junction with the neural tube. Obtain 3-dimensions as in Figure 2.

thelial cells $(\mathrm{n}=40)$, typically less than 10 in number (Fig. 5). PE cells were occasionally labeled, but so infrequently that they were not included in the analysis. 3) Two separate clusters of labeled cells in the NR ( $\mathrm{n}=$ 8). Such double clusters were not accompanied by any apparent abnormality of development, so we have included them in our analysis. We interpret them as the result of a unitary cluster of labeled cells being split apart during the interval following the injection, either by the incursion of unlabeled cells moving between the labeled ones or by independent movement of the labeled ones away from their neighbors. We injected at six widely separated sites (only one per vesicle), all defined with reference to the boundary of the vesicle (Fig. 7A). Five were in the LL: the rostral pole (i.e., slightly lateral to the junction of the vesicle and the optic stalk), the midpoints of the medial, caudal, and lateral margins, and the center of the LL. The sixth was in the ML. The locations of the labeled cells in the $24 \mathrm{hpf}$ NR were determined in fixed embryos (Fig. 6B, $\mathrm{C}$ ), and are illustrated in polar coordinates (r, the distance from the center of the retina to the end feet of the labeled cells; and $\Theta$, the angular location relative to the choroid fissure) on a planar representation of the retina (Fig. 6D).

The broad outline of the fate map was clear from the injections into the four marginal sites of the LL. The $r$-values of the labeled clusters did not depend system- atically on the injection sites, but the $\Theta$-values did. Rostral injections (Fig. 7B, Ro) produced labeled clusters that spread over about $60^{\circ}$, centered in ventronasal NR and in one case extending into the adjacent optic stalk. Two of the nine injections produced double clusters in which both members were quite close to one another. The medial injections (Fig. 7B, Me) labeled the nasal NR quadrant and were dispersed about as widely as the clusters from the rostral injection. The lateral injections (Fig. 7B, La) produced single clusters and 1 double cluster in temporal NR, dispersed over about the same area as the preceding injections. The caudal injections (Fig. 7B, Ca) produced single clusters dispersed more widely, as they spread over about $180^{\circ}$. This injection site also produced the highest fraction of double clusters (3/12), and two of them had individual clusters with $\Theta$-values that differed by about $90^{\circ}$. The wide distribution of single clusters and the large distance between the components of the double clusters indicate that cells on the caudal margin of the LL had less determined destinations in the NR than the other three marginal injection sites. Some underlying order was evident, as the mean $\Theta$-value of this distribution lay in dorsotemporal NR diametrically opposite to the mean of the distribution from rostral injections (Fig. 8). Thus, the counterclockwise progression around the rim of the left optic vesicle (rostral to lateral to caudal to medial to rostral) produced a counterclockwise progres- 


\section{Growth Data}

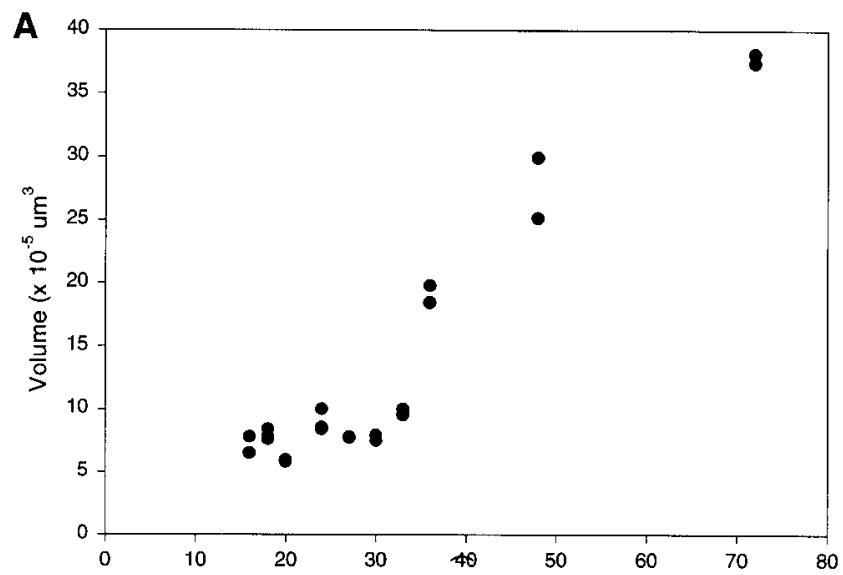

B

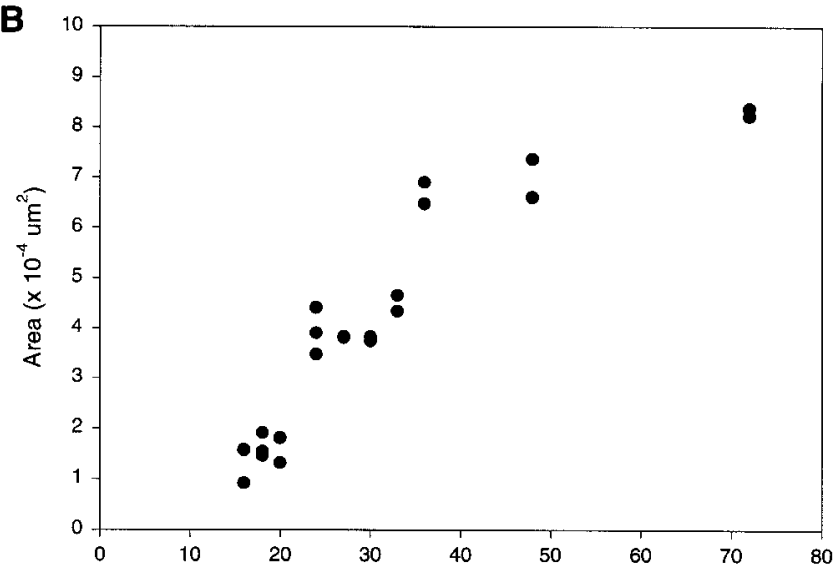

Age (hours post fertilization)

Fig. 4. Growth of the eye vs. age. Each symbol represents one eye. The data are uncorrected for shrinkage associated with histological processing. See "Experimental Procedures/Quantitative Morphometry" for details of the method. A: Volume of the whole eye (both the ML/PE and the LL/NR). B: Area of apposition between the ML/PE and the LL/NR.

sion around the central two-thirds of the left NR (ventronasal to temporal to dorsotemporal to nasal: Fig. 8), evidence that the cells on the margin of the vesicle were on average destined for a particular location in the NR. But the spread of the values and the existence of double clusters indicated that deviations from the average were not unusual. The central injections (Fig. 7B, Ce) were unique in that they produced two groups of descendants with different $\Theta$-values, one $(\mathrm{n}=5)$ in the central third of dorsonasal NR between the groups labeled by the medial and caudal injections and the other $(\mathrm{n}=6)$ in the middle third of ventrotemporal NR between the rostral and lateral groups. All of these injections produced single clusters, but each cluster lay in one of these two fairly restricted separate areas. Their r-values were also surprising because they were
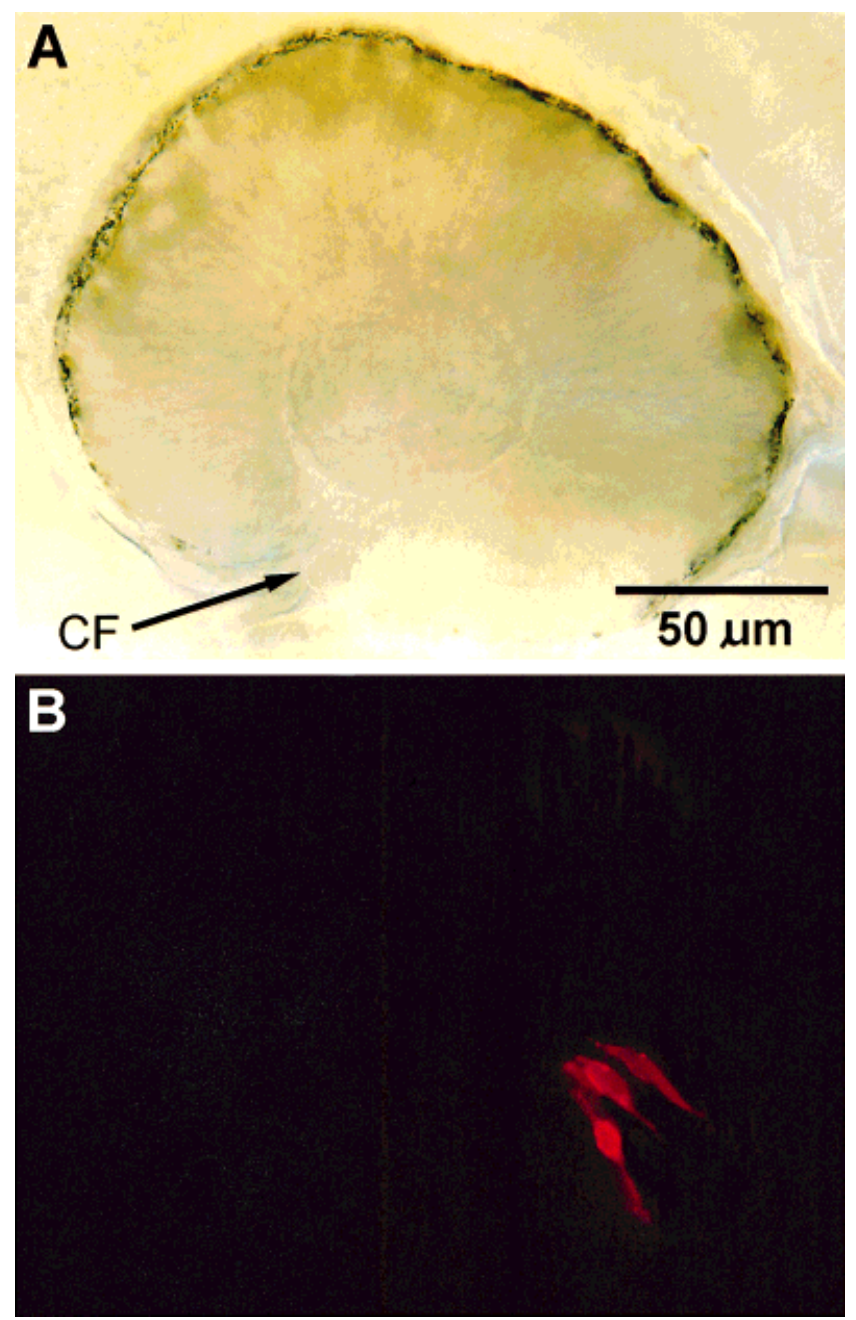

Fig. 5. Labeled cells in the $24 \mathrm{hpf}$ retina. A: Bright field image: lateral view of a left eye that was injected with dil at $15 \mathrm{hpf}$. Anterior to the left, dorsal up. CF: choroid fissure. B: Fluorescence image of the same field showing the dil-labeled cells.

similar to those of the cells labeled at the margin of the vesicle, which raises the question of where in the vesicle the cells in the center of the NR had originated. Finally, injections into the ventral edge of the ML yielded labeled cells in the peripheral third of the NR, and in one case (not shown) labeled only PE. In summary, the LL produced most of the central two-thirds of the NR and the ML contributed to the peripheral third of the NR. The fate map appeared to be approximately topographic in the sense that neighboring cells in the vesicle tended to remain neighbors in the NR, but the cells in the central part of LL were exceptions to the rule (Fig. 8).

Paired injections. Although the pooled data (Fig. 8 ) suggest that the fate map was orderly, the retinal locations of cells labeled at the "same" site in different individuals varied widely (Fig. 7B), and this variability raised the question of whether the vesicle-to-eye trans- 


\section{A Dorsal view of the optic primordium (14 hpf)}

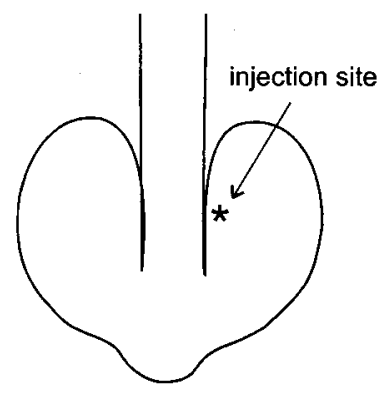

\section{Planar representation of the retina in polar coordinates $(24 \mathrm{hpf})$}

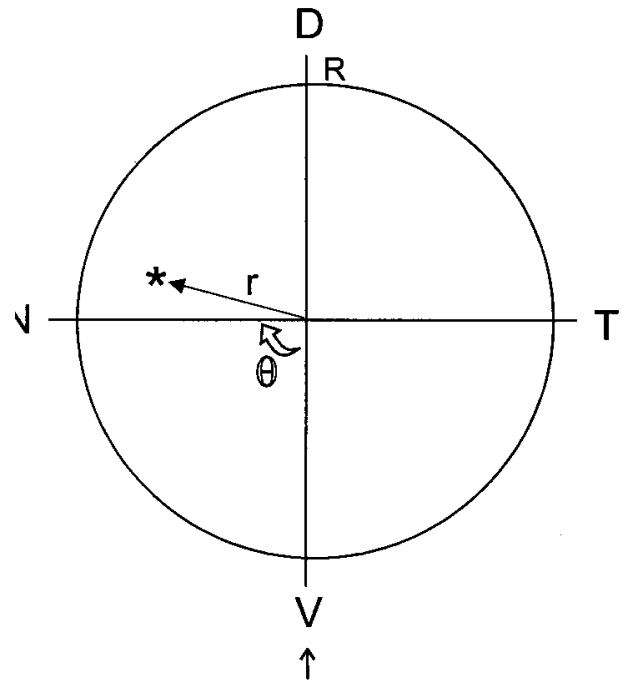

choroid fissure

Fig. 6. Construction of the fate map. See "Experimental Procedures/ Fate Maps" for details of the method. A: A dorsal view of a 14-15 hpf embryo, anterior downward, with the asterisk marking a medial injection site into the lateral layer (LL) of the left optic vesicle. B: Lateral view of the $24 \mathrm{hpf}$ eye resulting from the injection in A. The labeled cells are marked by *. The center of this view of the eye was located and taken as the origin $(r=0)$ of polar coordinates. The line through the center of the choroid fissure defines $0^{\circ}$ in the $\Theta$ coordinate. The $\Theta$-value of the labeled cells and the distance (b) from the center to the labeled cells were measured in the xy plane. Three locations in the z-direction were recorded: the lateral surface of the eye, the labeled cells, and the medial surface of the eye, from which the depth of the labeled cells relative to the depth of the whole eye (d) was obtained. C: The "standard eye" of a 24 hpf embryo is

formation was really orderly. Part of the variability was surely experimental inaccuracy (the experimenter's inability to inject at exactly the same site in differ-
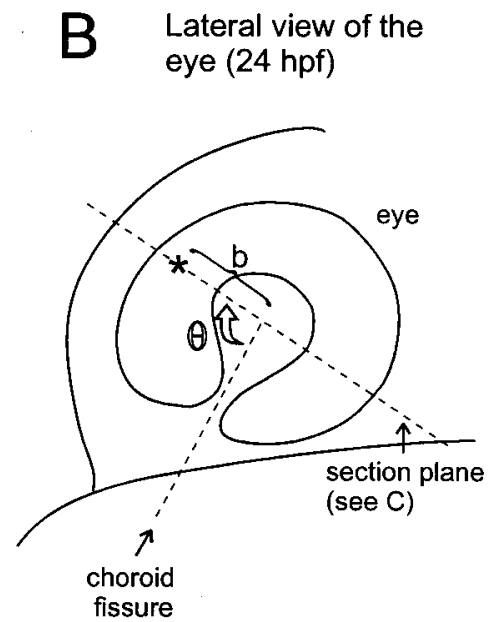

Cross section of
the eye (24 hpf)

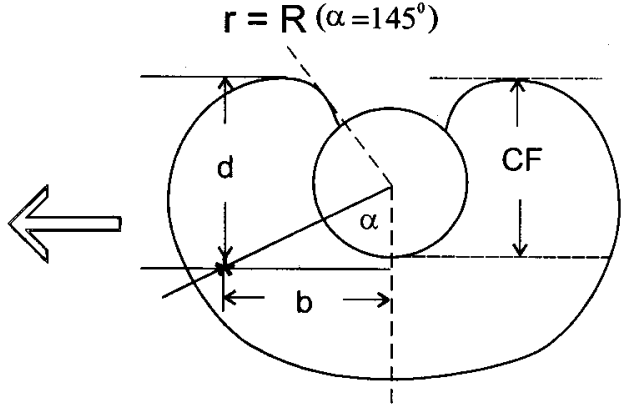

$r=0$ a section perpendicular to the view in $\mathrm{B}$. It was used to obtain the r-value of the labeled cells from the measured variables, $b$ and $d$. The vertical line connects the center of the lens and the center of the retina, and the labeled cells $\left(^{*}\right)$ are at the point b units away from the center line and $d$ units down from the lateral surface. A line drawn from this point to the center of the lens is parallel to the orientation of the column of labeled neuroepithelial cells in which the labeled cells lie. This line intersects the inner limiting membrane at the angle $\alpha$. The ratio, $\alpha / 145$, gave the $r$-value for the labeled cells normalized with respect to the "standard" eye, which subtends $145^{\circ}$ relative to the center of the lens. D: The $r$ - and $\Theta$-values are plotted on a 2-dimensional disk that is intended to represent a flattened en face view of the retina. The location of the labeled cells in this example are indicated $\left({ }^{*}\right)$.

ent individuals and to assign a valid retinal address to the labeled cells), but some of it might also reflect a randomness in the cellular rearrangements that oc- 


\section{A Six label sites}
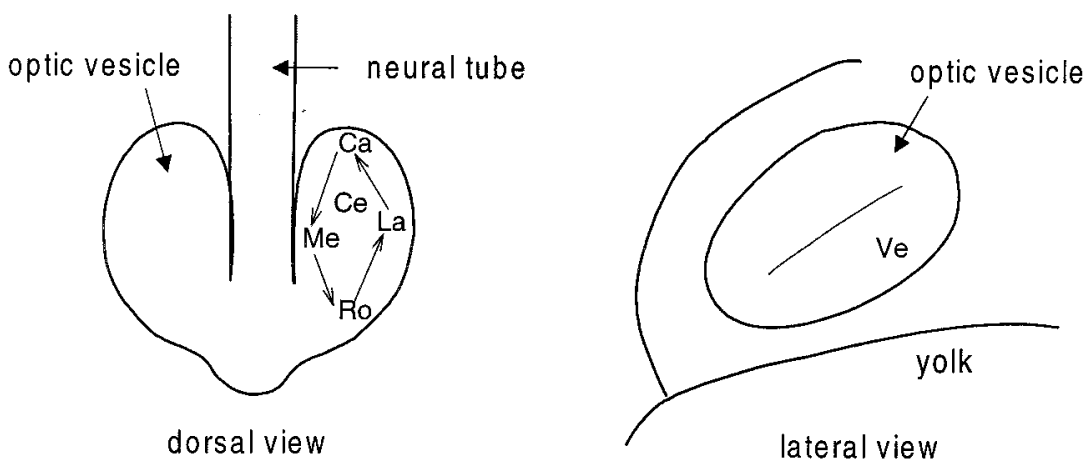

\section{B Locations of labeled cells in 24 hpf retina}

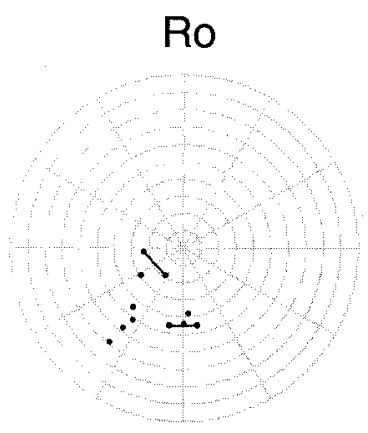

La

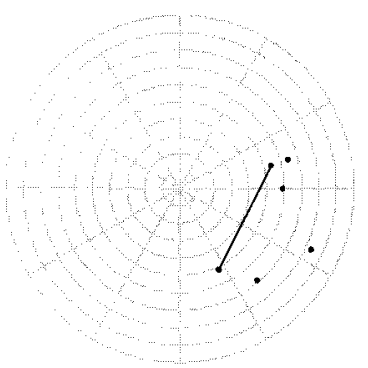

$\mathrm{Me}$

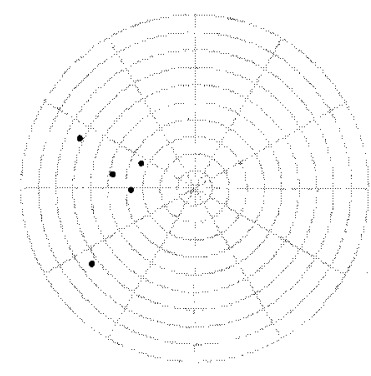

Ce

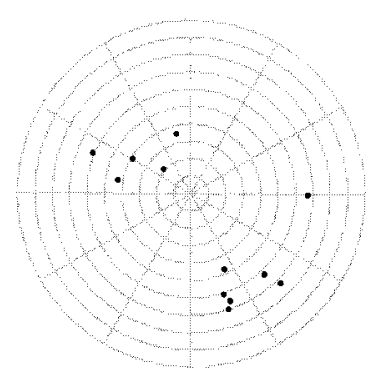

$\mathrm{Ca}$

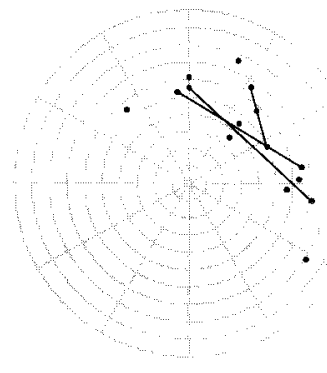

$\mathrm{Ve}$

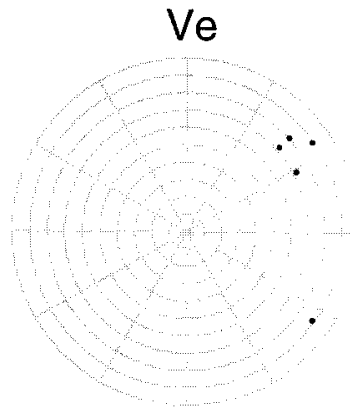

Fig. 7. Single injections. A: Schematic views of $14-15$ hpf embryo. Left: Dorsal view shows the five injection sites into the LL. Ro: rostral, Me: medial, Ca: Caudal, La: lateral, Ce: central. The four solid arrows trace a counterclockwise trajectory on the LL. Right: Lateral view, showing the injection site into the ML: Ve. B: The results of the injections into the individual sites shown in A. The planar representation of the left retina

curred during the formation of the eye cup. The occasional double clusters confirmed that some cells moved independently of their neighbors. Such independent movement has been documented in younger zebrafish embryos (Kimmel and Warga, 1986; 1987; Warga and Kimmel, 1990; Kimmel, et al., 1994), prior to the onset of organogenesis, but ocular morphogenesis appears to with the polar coordinates, $r$ and $\Theta$, shown in pale lines. Nasal (anterior) is to the left and dorsal is up. Each symbol represents the location of the center of a cluster of labeled cells resulting from one injection. Lines connecting pairs of symbols indicate that these two were members of a double cluster produced by the same injection.

involve mostly the movement of sheets of cells in which neighbor relations are more likely to be conserved.

To evaluate the extent of the randomness of the retinal fates, we made pairs of injections, a different colored dye at each, into the LL. The two injections straddled one of the canonical sites on the LL (Fig. 9A), and were separated by $10-20 \mu \mathrm{m}$ in a direction that 


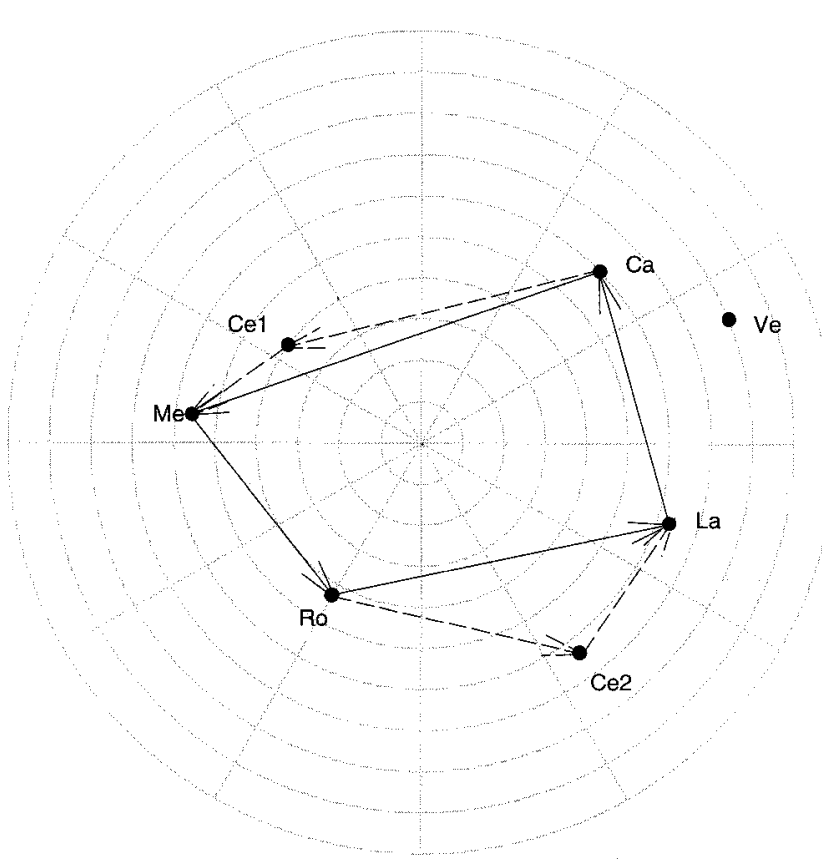

Fig. 8. Summary of the single injections. Planar representation of the retina as in Figure 7B. Each point shows the mean values of $r$ and $\Theta$ for the six injection sites, including two for the central injection. Abbreviations as in Figure 7; $\mathrm{Ce} 1$ and $\mathrm{Ce} 2$ indicate the two separate results from central injections. The solid arrows link the 4 sites labeled at the marginal injection sites, and trace a counterclockwise contour around the eye. The dashed arrows include the sites labeled at the central location.

would enable us to predict, according to the fate map in Figure 8, the relative $\Theta$-values of their descendants in the $24 \mathrm{hpf}$ NR. This approach allowed us to specify accurately the initial relative positions of the two labeled clusters, and if the fate map were really stochastic at the level of small clusters of cells, then we should find cells of the two colors in positions that were inconsistent with the fate map. For instance, a pair of injections on the lateral margin of the left vesicle, with the red label rostral to the green label, would be expected to produce labeled cells of both colors in the ventrotemporal quadrant, with the red cells the more ventral and the green cells the more dorsal. If the cells of the two colors were intermixed, or if the red cells were more dorsal than the green cells, the fate map would be indeterminate at this level of resolution.

Figure 9B shows the results, in which each arrow connects the red cluster (source of the arrow) to the green cluster (arrowhead). Arrows could not be drawn for 2 of the 14 injections (both rostral), because the more medial one labeled cells in the optic stalk and none in the NR. Of the 12 successful injections, 11 (6 rostral, 3 caudal, and 2 lateral) agreed with the prediction from the fate map. We conclude that the fate map was usually deterministic, down to the level of 10-20 $\mu \mathrm{m}$ on the vesicle, and the spread of Fig. 7B was due partly to the imprecision with which absolute addresses were assigned in both the vesicle and the NR.
But the production of double clusters from single injections suggests that deviations from local order occurred infrequently.

The paired injections into rostral vesicle produced additional information that suggested a cellular incursion that may account for the two lobes of the central injections. Most (6/7) of the bold arrows of Figure 9 point upward, showing that the retinal cells labeled at the more lateral of the two rostral sites systematically ended up at a more central location than those labeled at the more medial site. Both injection sites were on the margin of the vesicle, so this result indicates that the marginal cells from the more lateral of the paired injection sites occupied central NR, although their neighbors in both the clockwise direction (the lateral single injection site) and the counterclockwise direction (the rostral single injection site) ended up in more peripheral NR (Fig. 7B, 8). This implies that the rostrolateral margin of the vesicle had indented to bring some of the marginal cells into central NR. This was probably associated with the formation of the choroid fissure and the bulging outward of the epithelial sheet that produced the ventrotemporal NR. Thus the map of the margin of the LL onto the NR was a continuous contour but with an inward bend in the area of the choroid fissure. We suggest that this incursion may have displaced cells from the central region of the vesicle, and thus account for the two lobes that our central injections revealed (Fig. 7B, 8).

\section{DISCUSSION}

Our three-dimensional reconstructions of the optic vesicle and eye have advanced the original description of Schmitt and Dowling (1994) by including views of the optic stalk, the neural tube, and the medial surface of the eye which were not visible in scanning electron micrographs; by examining the growth of the eye quantitatively; and by extending our observations to $72 \mathrm{hpf}$. Our fate maps showed that the transformation from vesicle to eye mainly conserved intercellular neighbor relations, but not always, and that cells moved from the ML/PE to the LL/NR.

\section{Two Phases of Embryonic Eye Development.}

The conversion of the $16 \mathrm{hpf}$ vesicle, the first anatomically distinct eye primordium, to the $72 \mathrm{hpf}$ eye, the first seeing organ, occurred in two distinct phases: first a shape change with negligible growth, second, more modest shape change with rapid growth. During the first, 16-33 hpf, the two flat layers spread out to face one another across a larger curved surface that was at $24 \mathrm{hpf}$ nearly spherical $\left(290^{\circ}\right)$. This expansion in the area of the interface was effected with a substantial loss in volume of the ML/PE and a corresponding gain in the volume of the LL/NR, but the sum of the two volumes was essentially unchanged. During the second phase, 33-72 hpf, the nearly spherical eye became more nearly hemispherical, the adult form (Easter, et al., 1977), and both volume and area increased. The 


\section{A Injection sites}

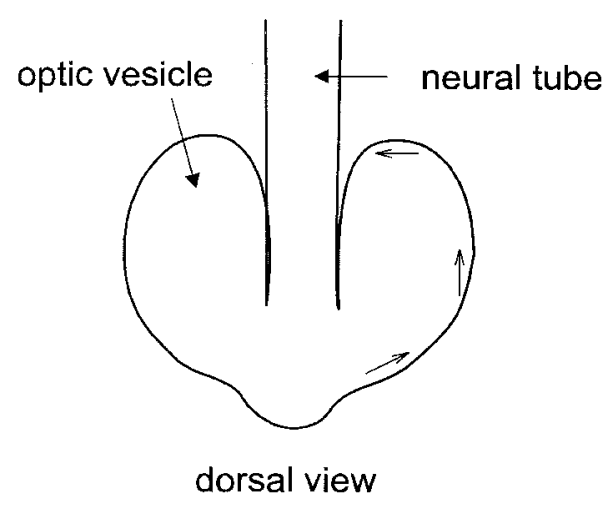

Fig. 9. Results of pairs of injection. A: Injection sites. Two closely spaced injections were made at either the rostral or the lateral or the caudal location. The ends of the thin arrows indicate the positions of the paired injections, red at the origin of the arrow and green or yellow at the arrowhead. B: Results of these injections. The planar representation of the retina as in Figure 6, 7. The arrows link the clusters that were

two phases correspond roughly to the pre-neurogenic and neurogenic, as the first neurons are born about 28 hpf (Nawrocki, 1985; Hu and Easter, 1999), and all three retinal nuclear layers were formed in central NR by about $60 \mathrm{hpf}$ (Hu and Easter, 1999), when synapses began to appear (Schmitt and Dowling, 1999). Most subsequent growth occurred at the proliferative retinal margin (Marcus et al., 1999), the adult pattern. This epimorphic growth also pushed the optic nerve head to a more central position in the retina.

The constancy of volume during the initial stage is consistent with earlier descriptions of morphogenesis in which the area of sheets of cells (such as the neural plate) varied reciprocally with their height (Gillette, 1944; Burnside and Jacobson, 1968), to be expected if volume were maintained constant. Here we have taken advantage of the physical isolation of the eye from other neural structures to measure the volume more precisely than was possible in those cases. The period during which the volume remained constant (16-33 hpf) extended beyond the time when cytokinesis had nearly ceased (16-24 hpf) (Li and Easter, 1997), therefore average cell volume must have decreased, as a comparison of Figure 1D and E suggests.

This two-stage program of enlargement (before and after $33 \mathrm{hpf}$ ) suggests an explanation for the five zebrafish mutants that are characterized by small NRs (Furutani-Seiki, et al., 1996). In four of them (spy eye, cleopatra, visionary, and podgladacz) the phenotype was apparent by 5 days post fertilization (dpf), and in one (out-of-sight) by $2 \mathrm{dpf}$. All had normal levels of cell death, so the small NRs can not have resulted from a loss of cells; subnormal growth must have been the cause. Apparently the abrupt onset of growth around

\section{B Locations in $24 \mathrm{hpf}$ retina}

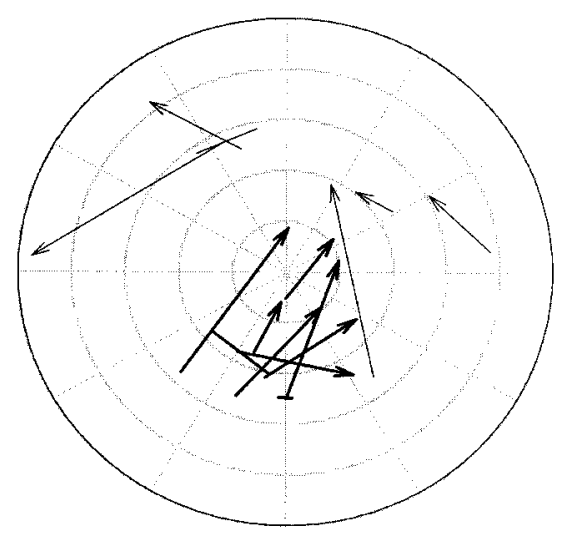

produced by the injections shown in A. The origin of the arrow indicates the red cluster, the arrowhead, the green/yellow cluster. Three of the red injections produced double clusters, which are connected by solid lines, and the arrows originate at their midpoints. The bold arrows indicate the injections at the rostral sites.

$33 \mathrm{hpf}$ was altered in the mutants, most severely in out-of-sight.

\section{Cell Rearrangement From ML to LL/NR}

The direct demonstration that cells in the ML of the vesicle ended up in the NR is instructive in two respects. First, it accounts for some of the reciprocal change in the volumes of the two layers; insofar as the ML lost cells to the LL, the two volumes of the two layers would be diminished and augmented, respectively. Second, it relates to the more general issue of cell movements in sheets, which Trinkaus (1984) has reviewed authoritatively. We briefly summarize the pertinent information (with quotations from p. 11 of that reference) and its potential application to ocular morphogenesis. First, invagination is defined strictly as "the inpocketing of an unbroken cell sheet, at a localized region, with no flow of additional sheet from beyond this locus" and evagination is defined as the reverse. A priori, the formation of the eye cup might have resulted from invagination of the LL and evagination of the ML, in the strict sense defined above, but our work has shown that this was not the case, as cells moved from ML to LL. To return to Trinkaus: this translocation of cells could occur by either of two routes: "ingression"(across the optic lumen) or "involution" (around the border between the two layers). We think that ingression is unlikely because we have examined many sections and have never seen a cell that spanned the optic lumen, as an ingressing cell would do. The fate map was consistent with either mode, because we labeled only peripheral cells from the ML, and found them in peripheral NR, where they could have arrived via either route. We favor involution, the 
movement within the sheet around the edge, like the tread on a Caterpillar tractor, because the images of Figure 1 support this mechanism. Figure 1B suggests that the dorsal cells in the ML that were cuboidal only two hours earlier (Fig. 1A) have become flattened and occupied a greater area of the ML, while the columnar ones in ventral ML slid around the lateral border of the optic lumen into the LL. The patch of squamous epithelium continued to spread away from its initiation site (Fig. 1C) and eventually covered the entire ML. To summarize, the progenitors of the PE were a small group of cells that spread to cover the entire ML as the majority of the cells in the ML moved around to the LL/NR during the formation of the eye cup. This interpretation is supported by the observation that the NR homeobox gene $Z r x 1$ is expressed at $18 \mathrm{hpf}$ in those $\mathrm{ML}$ cells that we believe are moving into the LL/NR, but not in those cuboidal and squamous cells that we claim are the precursors of the PE (Chuang et al., 1999). Holt (1980) also inferred from her studies of the Xenopus eye that cells involuted from the optic stalk to the NR, and independent evidence pointed to something similar in fish retinas (Easter, 1992), thus involution into the NR has a precedent.

The motive force causing involution is unknown, but the images of Figure 1A-C suggest two possibilities. Either the flattening dorsal cells of the ML pushed the more ventral ones around the edge or the ventral ones were pulled around the edge and in the process pulled the more dorsal ones and caused them to flatten. The pulling interpretation seems intuitively the more likely, given the abundant examples of contractile proteins that pull, but the flattening/pushing interpretation has support from neurulation in chick embryo, where the flattening epidermal ectoderm exerts a push on the lateral folds of the neural tube (Alvarez and Schoenwolf, 1992; Moury and Schoenwolf, 1995).

The shift of cells from the ML to the LL provides a mechanism for some earlier experimental results from the Dowling laboratory (Hyatt et al., 1992). Exogenous retinoic acid during early neurulation resulted in a "duplication" of the NR; that is, a crease developed in the center of the NR, producing a pair of concave surfaces which were in some cases associated with two lenses. Intermediate stages showed that the mutant ML did not thin down normally, and the portion of the ML that remained thick eventually swung out so that its basal surface faced laterally, thus forming the "duplicated" NR. All these features point to a failure of cells to move normally from the ML to the LL. The cells in the ML that were destined to become neurons failed to slide around the rim to the other side, as they would normally have done, and despite their ectopic location they continued their differentiative program and became neurons in a basally concave structure that resembled a duplicated NR. Although the proximate cause of the altered ocular anatomy was a failure of cell movement, the phenotype can also be interpreted as a failure at a higher level. The effect of retinoic acid on the formation of the body axis has been interpreted as the result of interference with patterning genes, particularly the Hox cluster, manifested by anterior structures adopting a more posterior identity (posteriorization: Marshall et al., 1992). Our fate map has shown that the "ventral" NR was actually derived from the anterior part of the vesicle adjacent to the optic stalk, which corresponds to the more anterior part of the neuraxis. The posteriorization idea would predict that excess retinoic acid should cause the presumptive ventral NR (the anterior region of the optic vesicle, in the coordinates of the early embryo) to behave like the dorsal NR (the part of the NR derived from more posterior vesicle). In fact, when the expression of regional markers was examined, excess retinoic acid enlarged the region with ventral markers and reduced the dorsal zone-retinoic acid ventralized the NR (Hyatt et al., 1996) - inconsistent with the prediction of posteriorization.

In a later article, Marsh-Armstrong et al. (1994) applied citral, a drug that interferes with the production of retinoic acid in ventral NR. The result (at $5 \mathrm{dpf}$ ) was a NR with no choroid fissure, and with an optic nerve that exited from the ventral side rather than the center of the eye. Recall that the choroid fissure developed between 20-24 hpf, and at $24 \mathrm{hpf}$ the optic stalk attached to the ventral side of the vesicle (Fig. 2C, 3A), but by $24 \mathrm{hpf}$, the choroid fissure had been formed and by $48 \mathrm{hpf}$ the optic nerve head was centrally located. Thus the citral treatment stopped ocular morphogenesis in ventral NR at around $20 \mathrm{hpf}$ by preventing the normal morphogenetic cell movements that create the ventral hemiretina and the choroid fissure. Our fate map showed that these regions all originate near the junction between the stalk and the vesicle, so citral must have had its effect on them. This is the zone of expression of the transcription factor, pax[b] (Pax2), which is believed to impart ventral retinal characteristics to cells in this region (Hyatt et al., 1996).

\section{The Fate Map}

Fate maps including the eye have been produced before (e.g., amphibian 2-cell blastula to late embryo: Jacobson and Hirose, 1978; amphibian neural plate to CNS: Eagleson and Harris, 1989; zebrafish gastrula to 24 hpf embryo: Woo and Fraser, 1995). The first and third involved largely mesenchymal cells, which frankly migrate relative to their neighbors, and the second involved morphogenesis by an epithelial sheet in which cells that begin together tend to remain together. Ours is the first to map the vesicle-to-eye transformation, lasting only $8-10$ hours, which is briefer than the others. The vesicle and the eye are both a pair of apposed epithelial layers, subdivisions of the CNS, and well isolated from other structures; these features suggest that the fate map would be rather simple and orderly but it proved to be neither. The destinations of cells in the vesicle were predetermined, but imperfectly. Injections into the central site produced a dis- 
tribution with two distinct lobes, not one large one. We suggest that cells from elsewhere in the vesicle invaded the center (involution), pushing the original central cells aside, some dorsonasally, the others ventrotemporally. Although such an incursion would cause a discontinuity in the fate map (neighboring cells in the center of the vesicle end up in non-neighboring regions of the NR), this may be an orderly event that regularly occurs. The other result that argues in favor of a stochastic element in the fate map is the production of double clusters by single injections. The initial injection was always confirmed as unitary at $14-15 \mathrm{hpf}$, so the pairs of labeled clusters that were sometimes seen at $24 \mathrm{hpf}$ must have resulted from a fragmentation of the initial one. In summary, the two-lobed distribution associated with central injections was probably a deterministic event associated with a predictable incursion of cells from the presumptive region of the choroid fissure into the center, but the occasional production of two clusters from one original one shows that cells near one another at one age sometimes ended up far apart a few hours later.

Neighbor relations have been examined elsewhere, with variable results. They are apparently maintained during mild deformations such as the formation of the amphibian neural plate (Burnside and Jacobson, 1968), but in more extreme deformations, such as the involution at the amphibian blastopore (Keller, 1978), neighbors change frequently. The conversion of the flat vesicle into the spherical eye cup has more in common geometrically with gastrulation than with the formation of the planar neural plate, so the change of neighbors is not surprising.

If such randomness and discontinuity are general features of eye development, they have implications for the specification of retinal addresses. In the projection of optic axons to the midbrain optic tectum, one of the most heavily studied axonal projections in the nervous system, the optic axons in anamniotes "know" their addresses when they initially grow out (Sakaguchi and Murphey, 1985; Holt and Harris, 1983; Kaethner and Stuermer, 1992). The projection is topographic, in the sense that neighboring ganglion cells in the NR project to neighboring sites in the tectum. If cells are to be assigned a two-dimensional retinal address (the process of "positional specification"), and if the addressing system is continuous, as is widely assumed (Gierer, 1983), then cells should be specified at a time when their neighbors are likely to remain neighbors in the NR. By that criterion, the specification should occur after the formation of the optic cup, but that prediction is inconsistent with an experimental study in Xenopus laevis (Sharma and Hollyfield, 1980). When eyes were rotated prior to the time when the vesicle had become cup-shaped (Grant et al., 1980), their axons projected as they would have done in their original orientation, evidence for specification having occurred prior to the formation of the eye cup. If so, then the misplaced cells might be apoptotically eliminated later. Alternatively, specification may not occur abruptly, but over hours, and the broad outlines are laid down in the vesicle and sharpened up in the NR through regionally correlated electrical activity (Wong, 1999).

\section{Embryos}

\section{EXPERIMENTAL PROCEDURES}

Adult zebrafish (Danio rerio) were obtained from local pet shops, and maintained in our own facility with a controlled light cycle of $14 \mathrm{hr}$ light/10 hr dark at $28.5^{\circ} \mathrm{C}$. They spawned soon after the onset of light, and the fertilized eggs were collected approximately $2 \mathrm{hr}$ after the lights came on. Embryos with the same number of cells (range 2-8) were sorted into individual petri dishes containing embryo rearing solution (ERS: $0.004 \% \mathrm{CaCl}_{2}, 0.0163 \% \quad \mathrm{MgSO}_{4}, 0.1 \% \mathrm{NaCl}$, and $0.003 \% \mathrm{KCl}$ ), and the dishes were labeled with the number of cells and the time of sorting and kept in an incubator at $28.5^{\circ} \mathrm{C}$. The first division occurs at $0.75 \mathrm{hr}$ post fertilization (hpf) and the next three divisions occur at $0.25 \mathrm{hr}$ intervals thereafter (Kimmel et al., 1995), so the exact time of fertilization was estimated by the cell number at the time of sorting.

\section{Morphogenesis}

Histology. Individual embryos (16, 18, 20, 24, 27, 30, $33,36,48$, and $72 \mathrm{hpf}$ ) were fixed in a mixture of $2 \%$ glutaraldehyde and $2 \%$ paraformaldehyde in $0.1 \mathrm{M}$ phosphate buffer, $\mathrm{pH}$ 7.4, rinsed, dehydrated in a graded series of ethyl alcohol, cleared in propylene oxide, and embedded in Epon. Sections (1 or $2 \mu \mathrm{m}$ thick) were cut on an ultramicrotome (Ultracut, American Optical), stained with toluidine blue, and coverslipped. All sections were saved, and the order carefully noted so that the embryos could be sampled at known intervals for quantitative analysis.

Three-dimensional images. Sections separated by $10 \mu \mathrm{m}$ were examined with $25 \times$ or $40 \times$ water-immersion objectives, and the outlines of the head, eye, and optic stalk/optic nerve were traced through a drawing tube onto translucent paper, and calibrated with a stage micrometer. The individual drawings were superimposed and aligned by eye, and four superimposable registration marks were put on each. The drawings were scanned digitally (Apple ColorOne Scanner, $150 \mathrm{dpi}$ ) and saved as Adobe Photoshop files. In Photoshop, individual drawings were cleaned and aligned, after which the original registration marks were removed. Stereo pairs were produced for each eye by placing the aligned stack next to a second stack made by shifting successive sections from the aligned stack a fixed number of pixels (2-4, depending on the age of the eye). The images are presented as three stacks of contours from which the reader can form stereo images (Fig. 2,3). The left and center images can be fused by diverging the eyes or using a stereo viewer, and the right and center images can be fused by converging the eyes. This presentation is used for two reasons. The first is that most people produce stereo images more 
readily by converging their eyes than by diverging them, and therefore any reader who lacks a stereo viewer will probably want to use the pair on the right. The second reason is that with the three images, it is possible to obtain the reversed perspective; e.g., in Figure 3 , convergent fusion of the right pair produces a lateral view of the left eye, and a convergent fusion of the left pair produces a medial view of the right eye.

Quantitative morphometry. Equally spaced semithin sections ( 1 or $2 \mu \mathrm{m}$ thickness) were drawn through a drawing tube. With a bit pad associated with a computer (MOP, Zeiss), two measurements were made from the drawings: the length of the optic lumen (the line along which the ML/PE faced the LL/NR) and the area of the ML/PE and LL/NR. Both measurements were expressed in terms of $\mu \mathrm{m}$ and $\mu \mathrm{m}^{2}$ on the section, using calibrations traced to a stage micrometer. When multiplied by the intersample interval, the length measurements produced the area of apposition between the $\mathrm{ML} / \mathrm{PE}$ and the LL/NR, and the area measurements produced the volume of these tissues.

\section{Fate Maps}

Cell labeling in the vesicle. Embryos of $14-15 \mathrm{hpf}$ were dechorionated and embedded in a thin layer of low-melting point agarose (A-5030, Sigma, St. Louis, $\mathrm{MO}$ ) on a microscope slide with a silver wire in electrical contact with the agarose. The slide was placed on a fixed-stage compound microscope (Laborlux, Leitz) and the silver wire was connected to the ground terminal on an electrical stimulator (Model S48, Grass). The embryos were positioned differently in the agarose depending on which layer was injected. Most injections were made into the LL, which was directly accessible to the micropipette (separated only by the skin), and for these, the embryo was oriented with this surface up and the micropipette entered orthogonally to the surface (Fig. 7A). Direct access to the ML was possible only from the side of the vesicle, so the embryos were rotated about $90^{\circ}$ for injections into this layer (Fig. 7A, right). Both left and right vesicles were injected, but all illustrations are illustrated as if on the left side.

Micropipettes were pulled from thin-walled capillaries (TW 100F-4, WPI) using a micropipette puller (Model P-87, Sutter). The tip of the micropipette was filled with a fluorescent marker, either diI , or diO (3, 3 '-dioctadecyloxacarbocyanine perchlorate, D-275, Molecular Probes), or diA (4-(4-(dihexadecyllamino)styryl)-N-methylpyridinium iodide, D-3883, Molecular Probes) dissolved in N,N-dimethylformamide $(2.5 \mathrm{mg}$ $/ \mathrm{ml}$ ) and then back-filled with 1.2 $\mathrm{M} \mathrm{LiCl}$. The active terminal of the stimulator was connected through a silver wire to the $\mathrm{LiCl}$ solution, and the micropipette was inserted into an electrode holder attached to a hydraulic drive (Frederick Haer) on a micromanipulator (Leitz). The tip was positioned under visual control through a long working distance $20 \times$ objective. A positive current was passed, and intermittently the epiillumination was shuttered on to monitor the fluorescent labeling. When a few cells were seen to be labeled, the current was stopped and the location of the injection site was noted on a sketch of the embryo (Fig. 6A). In most cases $(n=56)$ a single injection was made per vesicle, and this was always diI. Less often $(n=14)$, two injections were made at different sites in the same vesicle, diI at one site and either diO or diA at the other. Following the injection, embryos were quickly transferred to individual petri dishes containing warm ERS and returned to the incubator at $28.5^{\circ} \mathrm{C}$. At $24 \mathrm{hpf}$, they were anesthetized and fixed overnight in $4 \%$ paraformaldehyde in 0.1 M PIPES buffer (P-3768, Sigma), then cleared in $70 \%$ glycerine/30\% PIPES buffer. The age of $24 \mathrm{hpf}$ was chosen because it is the first age at which the eye cup is clearly spherical.

Labeled cells' locations in the eye cup. The twodimensional address of a retinal cell is the position of its endfoot on the outer limiting membrane. We used a modified polar coordinate system, in which the $\Theta$-value is the angle relative to the ray through the choroid fissure (Fig. 6B), and the r-value is the distance from the center of the NR along the curved retinal surface (Fig. 6C). To obtain the address of labeled cells from an external view of the intact eye, it is necessary to know the shape of the eye. We obtained the shape as follows. Uninjected $24 \mathrm{hpf}$ embryos $(\mathrm{n}=6)$ were processed through fixation and clearing similar to the diI-injected ones. They were mounted between two coverslips with the dorsal surface up, and examined on a compound microscope (Aristaplan: Leitz) equipped with differential interference (DIC) optics and a drawing tube. A through-focal series revealed the optical section containing the largest area of the lens, which was considered to pass through the center of the eye and was drawn. All were similar in shape, and approximated a partial sphere subtending $290^{\circ}$ about the center of the lens (Fig. 6C). This was used as the "standard eye" of a $24 \mathrm{hpf}$ embryo in the construction of the fate maps.

The labeled $24 \mathrm{hpf}$ embryos were mounted between two coverslips with the lateral surface of the eye oriented parallel to the glass and viewed in DIC optics. The eye was drawn to show the outer boundary, the choroid fissure, and the labeled cells (Fig. 6B). The distance from the center of the eye to the labeled cells was measured in the xy plane (b in Fig. 6B). In the $\mathrm{z}$ direction, three positions were recorded from the calibrated dial on the focus control: 1) the lateral surface of the eye (the part that first came into focus), 2) the center of the cluster of labeled cells, and 3) the medial surface of the eye (the last part to be in focus). The first and third gave the thickness of the eye, and the second gave the depth of the labeled cells (d in Fig. 6C). These data were used with the "standard eye" to obtain the rand $\Theta$-values of labeled cells.

The polar coordinates of the labeled cells in the 24 hpf eye cup are represented on a schematic two-dimensional representation of the NR viewed en face, with the values of both $\mathrm{r}$ and $\Theta$ plotted linearly (Fig. 6D, 7, $8,9)$. 


\section{ACKNOWLEDGMENTS}

We thank Prof. Charlotte Mistretta for her comments on the paper.

\section{REFERENCES}

Alvarez IS, Schoenwolf GC. 1992. Expansion of surface epithelium provides the major extrinsic force for bending of the neural plate. J Exp Zool 261:340-348.

Burnside MB, Jacobson AG. 1968. Analysis of morphogenetic movements in the neural plate of the newt Taricha torosa. Dev Biol 18:537-552.

Chuang JC, Mathers PH, Raymond PA. 1999. Expression of three Rx homeobox genes in embryonic and adult zebrafish. Mech Dev 84: 195-198.

Eagleson GW, Harris WA. 1989. Mapping of the presumptive brain regions in the neural plate of Xenopus laevis. J Neurobiol 21:427440.

Easter SS Jr. 1992. Retinal growth in foveated teleosts: nasotemporal asymmetry keeps the fovea in temporal retina. J Neurosci 12:23812392.

Easter SS Jr, Nicola GN. 1996. The development of vision in the zebrafish (Danio rerio). Dev Biol 180:646-663.

Easter SS Jr, Johns PR, Baumann LR. 1977. Growth of the adult goldfish eye-I: Optics. Vision Res 17:469-477.

Furutani-Seiki M, Jiang YJ, Brand M, Heisenberg CP, Houart C, Beuchle D, van Eeden FJM, Granato M, Haffter P, Hammerschmidt M, Kane DA, Kelsh RN, Mullins MC, Odenthal J, Nusslein-Volhard C. 1996. Neural degeneration mutants in the zebrafish, Danio rerio. Development 123:229-239.

Gierer A. 1983. Model for the retino-tectal projection. Proc R Soc B 218:77-93.

Gillette R. 1944. Cell number and cell size in the ectoderm during neurulation (Amblystoma maculatum). J Exp Zool 197:191-246.

Grant P, Rubin E, Cima C. 1980. Ontogeny of the retina and optic nerve in Xenopus laevis. I. Stages in the early development of the retina. J Comp Neurol 189:593-613.

Halfter W, Deiss S, Schwarz U. 1985. The formation of the axonal pattern in the embryonic avian retina. J Comp Neurol 232:466-480.

Holt C. 1980. Cell movements in Xenopus eye development. Nature 287:850-852.

Holt CE, Harris WA. 1983. Order in the initial retinotectal map in Xenopus: a new technique for labelling growing nerve fibres. Nature 301:150-152.

Hu M, Easter SS Jr. 1999. Retinal neurogenesis: the formation of the initial central patch of postmitotic cells. Dev Biol 207:309-321.

Hyatt GA, Schmitt EA, Marsh-Armstrong NR, Dowling JE. 1992. Retinoic acid-induced duplication of the zebrafish retina. Proc Natl Acad Sci USA 89:8293-8297.

Hyatt GA, Schmitt EA, Marsh-Armstrong N, McCaffery P, Drager UC, Dowling JE. 1996. Retinoic acid establishes ventral retinal characteristics. Development 122:195-204.

Jacobson M, Hirose G. 1978. Origin of the retina from both sides of the embryonic brain: a contribution to the problem of crossing at the optic chiasma. Science 202:637-639.

Kaethner RJ, Stuermer CA. 1992. Dynamics of terminal arbor formation and target approach of retinotectal axons in living zebrafish embryos: a time-lapse study of single axons. J Neurosci 12:3257-3271.

Keller RE. 1978. Time-lapse cinemicrographic analysis of superficial cell behavior during and prior to gastrulation in Xenopus laevis. J Morphol 157:223-248.
Kimmel CB, Warga RM. 1986. Tissue-specific cell lineages originate in the gastrula of the zebrafish. Science 231:365-468.

Kimmel CB, Warga RM. 1987. Indeterminate cell lineage of the zebrafish embryo. Dev Biol 124:269-280.

Kimmel CB, Warga RM, Kane DA. 1994. Cell cycles and clonal strings during formation of the zebrafish central nervous system. Development 120:265-276.

Kimmel CB, Ballard WW, Kimmel SR, Ullmann B, Schilling TF. 1995. Stages of embryonic development of the zebrafish. Dev Dyn 203: 253-310.

Li Z, Easter SS Jr. 1997. The development of eye in the zebrafish embryo. Abstr Soc Neurosci 23:1966.

Marcus RC, Delaney CL, Easter SS Jr. 1999. Neurogenesis in the visual system of embryonic and adult zebrafish (Danio rerio). Vis Neurosci 16:417-424.

Marsh-Armstrong N, McCaffery P, Gilbert W, Dowling JE, Drager UC. 1994. Retinoic acid is necessary for development of the ventral retina in zebrafish. Proc Natl Acad Sci USA 91:7286-7290.

Marshall H, Nonchev S, Sham MH, Muchamore I, Lumsden A, Krumlauf R. 1992. Retinoic acid alters hindbrain Hox code and induces transformation of rhombomeres $2 / 3$ into a $4 / 5$ identity. Nature 360:737-741.

Moury JD, Schoenwolf GC. 1995. Cooperative model of epithelial shaping and bending during avian neurulation: autonomous movements of the neural plate, autonomous movements of the epidermis, and interactions in the neural plate/epidermis transition zone. Dev Dyn 204:323-337.

Nawrocki L. 1985. Development of the Neural Retina in the Zebrafish, Brachydanio rerio. Ph.D. dissertation, University of Oregon, Eugene, OR

Ross LS, Parrett T, Easter SS Jr. 1992. Axonogenesis and morphogenesis in the embryonic zebrafish brain. J Neurosci 12:467482

Sakaguchi DS, Murphey RK. 1985. Map formation in the developing Xenopus retinotectal system: an examination of ganglion cell terminal arborizations. J Neurosci 5:3228-3245.

Schmitt EA, Dowling JE. 1994. Eye morphogenesis in the zebrafish, Brachydanio rerio. J Comp Neurol 344:515-536.

Schmitt EA, Dowling JE. 1996. Comparison of topographical patterns of ganglion and photoreceptor cell differentiation in the retina of the zebrafish, Danio rerio. J Comp Neurol 371:222-234.

Schmitt EA, Dowling JE. 1999. Early retinal development in the zebrafish, Danio rerio: light and electron microscopic analyses. J Comp Neurol 404:515-536.

Sharma SC, Hollyfield JG. 1980. Specification of retinotectal connexions during development of the toad Xenopus laevis. J Embryol Exp Morphol 55:77-92

Silver J, Sapiro J. 1981. Axonal guidance during development of the optic nerve: the role of pigmented epithelia and other extrinsic factors. J Comp Neurol 202:521-538.

Trinkaus JP. 1984. Cells into organs. The forces that shape the embryo. 2nd Edition. Englewood Hills: Prentice Hall. 543 p.

Walls GL. 1963. The vertebrate eye and its adaptive radiation. New York: Hafner. 785 p.

Warga RM, Kimmel CB. 1990. Cell movements during epiboly and gastrulation in zebrafish. Development 108:569-580.

Wong ROL. 1999. Retinal waves and visual system development. Ann Rev Neurosci 22:29-48

Woo K, Fraser SE. 1995. Order and coherence in the fate map of the zebrafish nervous system. Development 121:2595-2609. 